\title{
PRÁTICAS EDUCATIVAS DE EGRESSOS DA LICENCIATURA EM EDUCAÇÃO DO CAMPO IFPA/PROCAMPO, CASTANHAL, PARÁ
}

\author{
EDUCATIONAL PRACTICES OF GRADUATES OF THE UNDERGRADUATE COURSE IN \\ RURAL EDUCATION IFPA / PROCAMPO/IFPA, CASTANHAL, PARÁ
}

Márcia Cristina Lopes e Silva ${ }^{1}$

\begin{abstract}
Resumo: Este artigo traz parte das reflexões realizadas na tese de doutorado intitulada "Caminhos da interdisciplinaridade: da formação por área de conhecimento às práticas educativas de egressos da Licenciatura em Educação do Campo (LEdoC), do Instituto Federal do Pará (IFPA), campus de Castanhal. As discussões aqui apresentadas são resultantes da pesquisa qualitativa, e dos instrumentos metodológicos observação participante, entrevistas semiestruturadas e entrevista coletiva. A investigação partiu das observações das práticas educativas do trabalho com a interdisciplinaridade nas escolas em que atuam os educadores egressos da referida LEdoC. Foram entrevistados oito egressos que residem e atuam como educadores em diferentes localidades rurais na região do nordeste paraense, sendo também analisadas as suas práticas educativas e as influências do curso nas ações que estes desenvolvem em sala de aula. Nesse contexto, foi percebido que o curso contribuiu em práticas educativas contextualizadas, trazendo a problematização dos conteúdos escolares para a realidade dos estudantes.
\end{abstract}

Palavras-chave: Prática educativa; licenciatura em Educação do Campo; educação contextualizada.

Abstract: This paper brings part of the reflections made in the doctoral thesis entitled "Paths of interdisciplinarity: from training by area of knowledge to the educational practices of graduates from the Undergraduate course in Rural Education (LEdoC) of the Federal Institute of Pará (IFPA), campus of Castanhal", of the Doctorate in Education of the Federal University of Ceará (UFC). The discussions presented here are the result of qualitative research and methodological instruments, which were: participant observation, semi-structured interviews and collective interview. The investigation started from the observations of the educational practices of work with interdisciplinarity in the schools in which the educators graduated. In this context, eight (8) graduates of the LEdoC course were interviewed who reside and act as educators in different rural locations in the northeast region of Pará. The field research took place in 2015. During that year, the performance of the graduates was observed, analyzing their educational practices and the influences of the course on actions in the classroom. In this context, it was noticed that the course contributed to contextualized educational practices, bringing the problematic of school content to the students' reality.

Keywords: Undergraduate course in Rural Education. Educational Practice. Contextualized education.

\section{Introducão}

Este artigo traz uma discussão acerca da prática educativa de egressos da LEdoC, considerando que o processo de formação exige novas necessidades no que diz respeito às formas de elaboração e apropriação dos conhecimentos. Sabemos que esses conhecimentos, no âmbito da escola, encontram-se fragmentados e compartimentalizados nos modelos das disciplinas

\footnotetext{
${ }^{1}$ Instituto Federal do Pará, Belém, PA, Brasil.
} 
tradicionais, organizadas nas formas de currículos escolares, traduzidos em conteúdos, muitos dos quais dissociados da realidade concreta dos educandos. Assim, como pensar em uma prática educativa que vá de encontro a esses modelos normativos tão arraigados no chão da escola?

De acordo com os princípios e fins da educação nacional, a Lei de Diretrizes e Bases da Educação Nacional LDB 9304/96 assinala a necessidade de:

garantia de padrão de qualidade;

valorização da experiência extraescolar;

vinculação entre a educação escolar, o trabalho e as práticas sociais.

consideração com a diversidade étnico-racial.

Tais princípios que embasam a lei colocam a educação escolar com o desafio de inserir em sua proposta pedagógica tais recomendações. No entanto, é necessário ponderar que, para isso, o professor precisa ter uma formação que o permita não apenas ter esses conhecimentos, mas de um modo geral, saber como isso se traduz na prática educativa do seu fazer.

Sobre essa questão, Freire (2014) é enfático ao afirmar que: [...] "na formação permanente dos professores, o momento fundamental é o da reflexão crítica sobre a prática, de maneira que se pense na prática de hoje ou de ontem para melhorar a próxima”. (2014, p. 44). Nesse sentido, a prática educativa é dimensão da formação humana e está para além do campo pedagógico, pois compreende os processos que envolvem os educadores, a postura crítica em sala de aula, a vivência desses sujeitos nos seus espaços de atuação (escolas, comunidades, sindicatos e outros). Essas experiências contribuem para as análises e percepções de mundo, de classe, das condições de vida e da superação das desigualdades.

Para compreender as práticas educativas dos educadores egressos da LEdoC foi necessário a imersão na pesquisa de campo, através da observação participante e das entrevistas. Na organização das análises dos dados, a referência foi o método da análise de conteúdo (BARDIN, 2012). A organização se deu a partir da frequência das ideias que foram surgindo nos agrupamentos de falas. A partir daí, foi possível construir uma síntese que representou questões das categorias levantadas e que possibilitou uma sistematização dos dados colhidos com os sujeitos.

Foram entrevistados oito (8) egressos, que estão identificados no decorrer do artigo com nomes fictícios, e que residem e atuam como educadores em diferentes localidades rurais na região do nordeste paraense. A pesquisa ocorreu no ano de 2015. Durante o ano foram observadas as comunidades de atuação dos egressos, analisando as suas práticas educativas e as influências do curso nas ações em sala de aula. Nesse contexto, foi percebido que a LEdoC contribuiu em práticas educativas contextualizadas, na problematização dos conteúdos escolares, trazendo-os para a realidade vivenciada por alunos que residem em comunidades rurais.

O artigo está organizado em tópicos que discutem a prática educativa destes egressos, trazendo as reflexões destes educadores do campo, seus discursos, perspectivas e percepções de suas práticas pedagógicas, apontando os caminhos de uma educação contextualizada, que considere as vivências dos seus educandos para a socialização dos conteúdos a serem trabalhados em sala de aula.

\section{Prática Educativa: reflexões com educadores do campo egressos da LEdoC}

Um componente importante em uma prática educativa crítica está na ação-reflexão-ação, o que em Freire (2014) remete à relação de educadores e educandos. Ambos aprendem, apesar das diferenças, mas não se reduzem a meros objetos um do outro, sendo, ao contrário, sujeitos em interação com o conhecimento e experiências vivenciadas. Com isso, a problematização é 
o ponto de partida da percepção da realidade, principalmente no ato de pesquisar. Freire (2014) se refere ao ciclo gnosiológico na relação ensinar e aprender do conhecimento já existente, que está na dialética da análise sobre uma prática em que se melhora na atuação como educador e se aprende na sua função. Segundo Roseli (Egressa da LEdoC) entrevistada no ano de, 2015:

Me formei nos encontros regionais do MST, nas formações, nas ações diretas, nas ocupações. Isto contribuiu na minha prática educativa, pois vivi e me criei no movimento dialético, de pensar, se indignar e refletir as questões sociais, $e$ principalmente vivenciar no assentamento e na escola. A formação na Licenciatura me ajudou a relacionar essas experiências com os conhecimentos acadêmicos. Mas participar do Movimento foi fundamental para ser o que sou hoje.

A participação nos movimentos sociais contribui com a prática educativa dos educadores, como pode ser percebido no relato acima. Para Arroyo (2003), essas experiências deixam marcas nos sujeitos sociais, devido ao pensar e ao fazer educativo como foco de formação de seus sujeitos em ação coletiva, como os Sem Terra, Sem Teto, como sujeitos coletivos e históricos. Esses estão em movimento, trazendo as diversas experiências como momentos educativos, ao se apropriarem dos processos de produção e formação humana, reeducando-se nas interrogações e reflexões de suas origens e nas vivências de lutas.

O ser histórico e coletivo dos movimentos sociais, como os Sem Terra, coopera com a necessidade de ser organizado, e isto repercute na prática educativa das educadoras ligadas a esses movimentos, que buscam na associação de pais, nos conselhos escolares e nas associações de produtores do assentamento o envolvimento com as questões da escola, como projetos, enfrentamento com a prefeitura para a merenda escolar, e outros, assim como o envolvimento dos estudantes nas questões do ensino, nas místicas ${ }^{2}$ em sala de aula (cantam músicas do MST, leem poemas), e o frequente diálogo da relação entre realidade e os conteúdos das disciplinas.

Nas comunidades rurais em que foi realizada a pesquisa de campo, situadas na mesorregião do nordeste paraense, as prefeituras e os vereadores controlam as demandas da escola, as indicações de professores contratados, as direções e coordenações pedagógicas. E os educadores egressos da LEdoC, apesar de tentarem aglutinar os pais e o corpo escolar, na maioria das vezes estão sós, e acabam por focar suas atividades em sala de aula, estabelecendo relações do conteúdo com a realidade dos alunos. Tanto os educadores que são vinculados aos movimentos sociais, quanto os demais, enfocaram, nas conversas que tivemos, a necessidade da problematização do ensino, refletindo sobre os significados e as necessárias relações com as vivências dos estudantes.

A reflexão sobre a educação problematizadora contribui na apropriação da prática educativa dialógica, no reconhecimento do ser enquanto histórico, incompleto e em constante diálogo com a natureza e a cultura, estas últimas inerentes ao processo de existência humana. Assim, fundam-se as relações entre os sujeitos e suas interações consigo e com o outro. E o ato de educar se mistura à atenção com o contexto em que se está situado, pois "saber se funda na comunhão com os outros saberes para compreender a sociedade que se tem e a que se quer" (FREIRE, 2001, p. 45).

Por isso, os educadores egressos da LEdoC buscam a interação pedagógica com seus alunos, através da aproximação do conteúdo com a realidade, na reflexão com a problematização do ensino, através de questões pertinentes à comunidade. Outro elemento importante consiste na reflexão de que a educação é um processo inacabado, que se faz na busca constante, como elucida Rosa (Egressa da LEdoC, ano de 2015), "tenho cotidianamente uma

\footnotetext{
${ }^{2}$ Para aprofundamento acerca do significado da mística do MST, ver MEDEIROS, Evandro Costa. A dimensão educativa da MÍSTICA SEM TERRA: a experiência da Escola Nacional "Florestan Fernandes". PPGECED/UFSC. Florianópolis SC, 2002.
} 
prática reflexiva, mas para isso, preciso repensar todos os dias, o que vou trabalhar, como, quais relações posso fazer com a comunidade, e assim vou aprendendo."

Os desafios postos aos educadores do campo são muitos, e, na maioria das vezes, esses acabam realizando ações individuais, pela dificuldade de se trabalhar no coletivo da escola, mas mesmo assim, vão chamando a atenção dos alunos e demais professores, principalmente por compreenderem o movimento dialético e dinâmico que envolve a escola, movimento que Freire (2001, p. 42) aponta como o necessário "entre o fazer e o pensar sobre o fazer".

A prática educativa no cotidiano remete à discussão da práxis libertadora, que na autoanálise da ação pedagógica do ser educador pressupõe a transformação do ensino e da realidade, fundada no diálogo e na reflexão. Pois, sendo a práxis histórica e social, essa contribui na reflexão que Freire (1987) chamou de passagem da consciência ingênua à possibilidade da crítica e da transcendência.

Nesse contexto, a categoria diálogo, em Freire (1992), além de possibilitar a interação, também é considerada um fenômeno humano, fruto da existência. Através da relação do indivíduo consigo mesmo, com o outro e com a sociedade, mediada pelo exercício da análise crítica o que se busca é aprofundar o nível de conhecimento, ou seja, os conteúdos de ensino são frutos desse levantamento trazido das relações dialógicas. $\mathrm{O}$ ato de questionar com seus educandos, acerca das suas compreensões, é um momento de inquietação de ambos, educadores-educandos, e isto possibilita dar significado ao ato de ensinar e de aprender.

$\mathrm{Na}$ educação libertadora, a tarefa do educador dialógico é trabalhar em equipe interdisciplinar, iniciando-se com o levantamento do universo temático vivenciado pelos educandos recolhidos através da investigação in loco, espaço onde vivem os educandos, para a compreensão das suas realidades e intervenções.

No processo de contextualização do ensino, tendo em vista o levantamento do tema gerador, existem alguns apontamentos trazidos por Freire (1987). Por exemplo, quando um grupo de indivíduos não expressa as suas inquietações, pode-se trazer para a discussão um tema dramático, ou mesmo se pode trabalhar o silêncio enquanto sugestão de uma problemática que pode ser identificada. Geralmente, essa postura do não falar é resultante das "situações-limite" que foram vivenciadas pelos indivíduos. É nesse sentido que "o processo de busca da temática significativa já deve estar presente na preocupação pela problematização dos próprios temas, por suas vinculações com outros. Por seu envolvimento histórico cultural" (FREIRE, 1987, p. 57).

A criticidade é condição fundamental para a leitura da palavra e do mundo. Assim, Freire (2014) traz essas interpretações que provocam insatisfações em relação ao que está posto, podendo, a partir daí, gerar a transcendência, pois o acesso ao ensino crítico demanda uma compreensão que faz do investigar e do fazer ciência o ato de "descobrir, desvelar verdades em torno do mundo, dos seres vivos, das coisas, que repousavam à espera do desnudamento" (FREIRE, 1997, p. 68). Na medida em que se descobre e se compreende o significado da apropriação do conhecimento, é possível desvelá-lo.

$\mathrm{Na}$ ação do educador, somente a prática não é suficiente para suprir as demandas que envolvem os processos pedagógicos, pois teoria e prática são interligadas, complementando-se, o que se efetiva na práxis, através das reflexões sociais, políticas, econômicas, educacionais e outras. Vázquez (1977) destaca que a práxis é uma ação consciente e transformadora das mudanças sociais, pois é uma atividade humana que se manifesta na e a partir da realidade. Refletir sobre a prática educativa como ação transformadora da realidade em uma perspectiva crítica pressupõe considerar as contradições de classes como instrumento de concepção da sociedade em que se vive, compreendendo sua dinâmica e sua superação.

A relação teoria e prática voltada para uma práxis transformadora também se faz de fundamental importância no campo da formação do educador, o que, segundo Bernardes (2009), 
necessita do alimentar-se das teorias para explicar as ações que ocorrem no cotidiano da escola e nos diversos espaços educativos. Nesse contexto, a LEdoC contribuiu com seus educandos, ao trabalhar em todos os semestres as observações, intervenções e análise das questões referentes à comunidade e à escola, para buscar entender as dimensões que ocorrem nesses espaços, no sentido político, da gestão educacional, nas dinâmicas da produção e demais temáticas que permearam a alternância pedagógica, enquanto metodologia de aprendizagens que envolviam as observações da comunidade, e da escola, relacionadas com as discussões propostas pelas disciplinas no curso.

\section{Prática educativa de egressos da LEdoC: reflexões com a educação contextualizada}

A análise da prática educativa dos egressos da LEdoC foi pautada nas entrevistas e nas observações. Foi feita uma reflexão em torno da formação que os egressos tiveram na LEdoC, cotejando-as com as suas práticas educativas, sendo ambas relacionadas à interdisciplinaridade.

Os educadores analisados apresentaram em suas práticas preocupação no que se refere à compreensão dos conteúdos por parte de seus alunos em sala de aula, o que remete à necessidade de reflexão sobre o assunto que está sendo trabalhado, e que precisa ser fruto das observações do cotidiano, da relação educador-educando. Isso contribui na dimensão reflexiva da atividade, o que remete à práxis, no sentido de transformar a realidade, e construir e reconstruir saberes, trazendo possibilidades de diálogo, de interpretações sobre suas vivências docentes. Nesse contexto, apontase para uma prática educativa contextualizada, a partir da relação do conteúdo com a realidade, como apresenta o quadro abaixo, fruto das entrevistas com os egressos da LEdoC. Construiu-se um quadro síntese, com as falas; a ideia central que as resume e a quantidade de vezes que elas foram citadas nas entrevistas, conforme se pode observar a seguir.

\begin{tabular}{|c|c|c|}
\hline \multicolumn{3}{|c|}{ Tópico de discussão: Prática Educativa contextualizada } \\
\hline Conteúdo da mensagem/fala do sujeito & Ideia básica & Frequência \\
\hline $\begin{array}{l}\text { Quando falo de água, abordamos os igarapés que banham a comunidade, } \\
\text { não adianta encher o aluno de conteúdo, precisa ter o alicerce, saber a } \\
\text { base" (Josias, Egresso da LEdoC, 2015). } \\
\text { Conto uma história do imaginário local que é a cobra de fogo, os } \\
\text { alunos paralisam e ficam em silêncio, como se estivessem encantados } \\
\text { (Clara, Egressa da LEdoC, 2015). } \\
\text { Nas escolhas do conteúdo tento relacioná-lo com a realidade dos } \\
\text { alunos (Luís, Egresso da LEdoC, 2015). } \\
\text { Levo os alunos a conhecerem a realidade (Tereza, Egressa da LEdoC, 2015). } \\
\text { Na minha prática educativa faço a diagnose tenho conhecimento sobre o } \\
\text { lugar (Roseli, Egressa da LEdoC, 2015). } \\
\text { Traz o assunto para a realidade do assentamento (Isabel, Egressa da } \\
\text { LEdoC, 2015). } \\
\text { Utilizo as experiências dos alunos, e o que já conhecem em sua } \\
\text { localidade, no momento de explicação do conteúdo escolar (Josiel, } \\
\text { Egresso da LEdoC, 2015). } \\
\text { Quando se trabalha a realidade se concentram no assunto (Rosa, } \\
\text { Egressa da LEdoC, 2015). } \\
\text { Me esforço em fazer a relação da disciplina de matemática com o } \\
\text { cotidiano dos alunos (Clara, Egressa da LEdoC, 2015). }\end{array}$ & $\begin{array}{l}\text { Relacionar } \\
\text { conteúdo a } \\
\text { realidade dos } \\
\text { educandos }\end{array}$ & (9) \\
\hline
\end{tabular}

Quadro 01- Prática educativa contextualizada - Fonte: Pesquisa de campo, 2015. 
No quadro 01 sinalizou-se para uma prática educativa contextualizada, quando se relaciona o conteúdo com a realidade dos educandos. Foi observado, portanto, na pesquisa de campo, que os educadores buscavam despertar a curiosidade de seus alunos, pela atenção dispensada quando conseguiam em um determinado assunto, na maioria das vezes de uma disciplina, considerar a cultura local e as experiências que os educandos vivem. Esses aspectos fazem jus ao exercício de educador que vão se formando na relação com a sala de aula, com a escola, com a comunidade e na LEdoC.

Ao relacionar o conteúdo à realidade, os sujeitos conseguem estabelecer um diálogo maior entre o ensinar e o aprender. Parece que o conteúdo deixa de ser estranho e passa a ser conhecido, a ser compreendido. Quando os educadores começavam um assunto e estabeleciam a relação com o que acontece na comunidade, os alunos queriam participar, para dizer como acontecia, e, com essa curiosidade, aguçava-se a aula, tornando-se a mesma participativa e incentivadora.

Nesse sentido, a opção pelo termo prática educativa se deu por compreendê-la no âmbito mais abrangente. Segundo Silva e Ramos (2006, p. 1) “é uma prática social específica de caráter histórico e cultural que vai além da prática docente, abrange os diferentes espaços, a escola, a relação com a comunidade e a sociedade". Isso pressupõe tomada de decisão, para poder contribuir no trabalho coletivo e na gestão democrática. Essas questões estão envolvidas com a trajetória que esses educadores, que são sujeitos da pesquisa, vão construindo em sua comunidade e movimentos sociais.

Freire (1992) e Arroyo (1989) trazem a reflexão da prática educativa relacionada à prática social, ao compreenderem que educadores têm espaços próprios de atuação, e a sala de aula é um desses espaços. Os educadores que participaram da pesquisa de campo são envolvidos com as demandas políticas, sociais, educacionais e culturais do assentamento e da comunidade em que residem, conseguindo, na ação em sala de aula, relacionar o conteúdo escolar com a realidade dos seus alunos. Isso demostra que o exercício da prática educativa não se faz apenas no sentido de ensinar conteúdos, mas na formação humana, como possibilidade de reflexões críticas, ou seja, educador e educando, ambos sujeitos do processo de aprendizagem.

Nessa perspectiva se enfatiza o ato educativo e social, de caráter histórico e cultural, que vai além da docência, relacionado às atividades didáticas dentro da sala de aula, abrangendo diferentes aspectos, como as relações da escola, comunidade e a sociedade. Tal perspectiva pressupõe análises e tomadas de decisões em processo, articulando o trabalho coletivo e a gestão democrática. Como afirma Veiga (1992, p. 16), a prática educativa é "uma prática social orientada por objetivos, finalidades e conhecimentos, e inserida no contexto social, portanto a prática educativa é uma dimensão da prática social".

Constatou-se que há, por parte dos educadores egressos da LEdoC pesquisados, um real investimento de tempo e trabalho no que diz respeito a relacionar os conteúdos ensinados à realidade de seus educandos. Também encontrou-se igual preocupação em enfocar a importância do diálogo como modo de apropriação e socialização do conhecimento científico, o que traz a necessidade de se discutir a concepção de educação contextualizada, que está relacionada à opção metodológica do professor, mas, sobretudo, ao seu envolvimento enquanto prática social, com as demandas da escola e da comunidade.

Para Rodrigues e Amaral (1996), contextualizar a educação significa relacioná-la à realidade do aluno, não apenas como ponto de partida para o processo de ensino e aprendizagem, mas para o próprio contexto sócio-histórico, em que estão envolvidos os educados. Para isso, devem-se oferecer ambientes e atividades que propiciem a vivência de situações reais, concretas e práticas. O contexto, como elemento importante, possibilita ao educador intervir nas diversas vivências dos alunos, e isto contribui com a aprendizagem, pois aprender com significado tem mais sentido. 
Bandeira e Ibiapina (2014) referem-se à importância da prática educativa, como forma de se envolver e se atualizar conforme as necessidades do contexto sócio-histórico dos educandos, e isto influencia o exercício da práxis, quando a mesma é manifestada na intrínseca relação teoria-prática, o que possibilita a emergência da prática transformadora.

Nesse contexto, está a necessidade do engajamento dos educadores comprometidos com a escola e a comunidade, como foi observado na pesquisa de campo, quando da atuação das egressas, que são assentadas da reforma agrária, e do educador, que não está em sala de aula, mas que desenvolve um importante papel de articulador político e cultural de seu munícipio. Esses sujeitos participam de movimento sociais, como o MST e da associação de moradores, e isso tem contribuído com uma prática educativa contextualizada. Quanto aos demais, que são egressos da LEdoC, e educadores do campo, na ocasião da pesquisa, foi observado a preocupação na seleção dos conteúdos escolares e a aproximação com a realidade dos educandos.

As questões citadas são importantes quando se refere à necessidade de denúncia, de organização por parte da escola e da comunidade nos enfrentamentos das suas necessidades, e de seu protagonismo nas lutas sociais.

Nesse sentido, desenvolver uma educação que busque contextualizar o processo de ensino aprendizagem com a cultura local, trazendo suas demandas e necessidades para dialogar com o conteúdo escolar, é para, Macêdo (2008), o processo de interação entre sujeito-sujeito, sujeito e contexto e contexto e escola. Nessa relação, se constroem conhecimentos individuais e coletivos, através da memória coletiva, dos valores e das tradições. Relacionar os saberes locais e as experiências dos educandos possibilita uma diversidade de contextos, inclusive identificando as necessidades das comunidades, e municípios e contribuindo com a organização para a melhoria de suas condições de vida.

Na prática educativa dos sujeitos da pesquisa, observou-se a preocupação do diálogo com seus alunos, e, para que esse momento faça parte da dinâmica das aulas, se busca contextualizar os conteúdos, através de pesquisas na comunidade, como por exemplo, as histórias do imaginário popular. Para Freire (1987), não se pode tratar o conhecimento como algo estático e alheio ao que o estudante vive, ou seja, é preciso uma educação contextualizada e promotora de uma formação crítica e interdisciplinar. Por isso, o autor propõe os temas geradores, uma alternativa de diálogo e construção do conhecimento, de forma totalizante.

$\mathrm{Na}$ pesquisa de campo, no que se refere às proposições nas práticas educativas, elas apresentaram a palavra geradora, como uma articulação de várias disciplinas, e o diálogo na construção, como demostra o quadro a seguir: 
PRÁTICAS EDUCATIVAS DE EGRESSOS DA LICENCIATURA EM EDUCAÇÃO DO CAMPO...

\begin{tabular}{|c|c|c|}
\hline \multicolumn{3}{|c|}{ Tópico de discussão: proposições na prática educativa } \\
\hline Conteúdo da mensagem/fala do sujeito & Ideia básica & Frequência \\
\hline $\begin{array}{l}\text { Trabalho com palavras geradoras, são palavras que fazem parte do } \\
\text { dia a dia" (Izabel, Egressa da LEdoC, 2015) } \\
\text { Meu planejamento inclui a palavra geradora, por exemplo a juquira }{ }^{3} \\
\text { (Roseli, Egressa da LEdoC, 2015) } \\
\text { Desenvolvo várias atividades e sempre são dialogadas no coletivo. Trabalho } \\
\text { com cultura, memória e história (Josiel, Egresso da LEdoC, 2015). } \\
\text { Na minha prática educativa consigo envolver em uma atividade várias } \\
\text { disciplinas, através de um tema (Rosa, Egressa da LEdoC, 2015) } \\
\text { Através de uma historinha relaciono um tema e várias disciplinas } \\
\text { (Luís, Egresso da LEdoC, 2015). } \\
\text { Dentro da minha prática utilizo o diálogo, construir coletivamente, se } \\
\text { construímos juntos vem o sentimento de pertencimento. (Josias, } \\
\text { Egresso da LEdoC, 2015). } \\
\text { Desenvolvo atividades dialogadas, envolvendo outros atores, } \\
\text { construindo juntos. (Clara, Egressa da LEdoC, } 2015 .\end{array}$ & $\begin{array}{l}\text { Palavra } \\
\text { geradora } \\
\text { envolvendo } \\
\text { várias } \\
\text { disciplinas } \\
\text { Diálogo na } \\
\text { construção } \\
\text { coletiva }\end{array}$ & $(04)$ \\
\hline
\end{tabular}

Quadro 02 - Proposições na prática educativa. - Fonte: Pesquisa de campo/2015

No quadro 02, como pode ser observado, foram percebidas duas questões que apareceram com frequência. Uma refere-se à palavra geradora, buscando envolver várias disciplinas na prática educativa dos educadores egressos da LEdoC, e a outra se refere ao diálogo na construção coletiva. Na fala de Josias (Egresso da LEdoC, 2015), de que do construir coletivamente vem o sentimento de pertencimento, e isto contribui na qualidade da educação que se pretende na escola.

Apesar de apresentarem a existência ou mesmo necessidade da construção coletiva na escola, o que foi visto na pesquisa de campo foram atividades individuais dos professores em sua sala de aula. Havia reuniões de planejamento e de organização de programações comemorativas na escola, que eram os momentos de diálogos coletivos. Mas não como uma dinâmica da unidade de ensino, de caráter deliberativo e dialógico, e sim como parte de uma hierarquia da direção escolar, trazendo as demandas da Secretaria de Educação, para serem executadas.

Kramer (2003) destaca a importância da dimensão coletiva no trabalho escolar, ao considerar a necessidade de diálogo e de se assumir uma organização que possa considerar as demandas da escola para poder reivindicar a partir de suas necessidades, pois unidos, mesmo com as diferenças, os educandos podem ter objetivos comuns, como a qualidade do ensino.

No que se refere às palavras geradoras, envolvendo várias disciplinas, elas estão nas atividades da prática educativa em sala de aula, quando os educadores egressos da LEdoC buscam, através de diálogo com seus educandos, relacionar uma palavra ou tema que expressa sua realidade, como o que foi apontado por Roseli (Egressa da LEdoC, 2015), "meu planejamento inclui a palavra geradora, por exemplo, a juquira”, que é uma vegetação necessária, de ser preservada, antes de outros plantios. Para Freire (1987), trata-se de uma prática explicada como a adoção de situações que cercam a realidade de educandos e educadores.

Palavras geradoras podem ser frutos de discussões e contextualizações decorrentes da aproximação com a realidade de educandos-educadores. Para Barreto (1998), palavras são assuntos que geram discussão, investigação. Tal terminologia foi substituída por Freire (1987)

\footnotetext{
${ }^{3}$ Juquira: Segundo (Roseli, Egressa da LEDOC, 2015) Esse termo é utilizado para o mato que cresce no campo, ou em áreas abandonadas, principalmente quando se troca a área de plantio por outra, para ter o descanso, aí ficam as juquiras.
} 
por temas geradores, pois esses trazem situações que cercam a realidade, são objetos de conhecimentos, e necessitam do trabalho coletivo.

Nesse contexto, os sujeitos apontam para as palavras geradoras envolvendo várias disciplinas, mas com uma ação isolada na sala de aula, e não como iniciativa da escola, do Projeto Político Pedagógico, do trabalho coletivo. Elementos esses necessários de serem envolvidos, quando se trata dos temas geradores, pois apresentam uma outra lógica de seleção de conteúdos partindo da investigação, problematização, e dos temas decorrentes da realidade dos educandos, implicando em um trabalho com a interdisciplinaridade, agregando as diversas áreas do conhecimento, como um meio de concepção da educação, que requer práxis, associando teoria e prática na ação reflexiva de educadores, escola e comunidade.

É importante mencionar que nas escolas encontram-se educadores que vêm lutando para se trabalhar com metodologias, reflexões e críticas, como exemplo, por exemplo, pela utilização da palavra geradora, como apontaram dois sujeitos da pesquisa, ao se referirem a um momento que envolve várias disciplinas em sala de aula. Essa possibilidade de integrar saberes a partir de um tema proporciona a investigação e a problematização, para se poder relacionar a pesquisa como necessária no aprendizado dos educandos. Os desafios estão postos, e podem ser enfrentados pelo educador, com compromisso e articulação em seu coletivo, dentro do seu papel político e pedagógico.

Todavia, na prática dos sujeitos pesquisados, observou-se que as aulas são ministradas por disciplina, e em poucas vezes, essas estabeleceram relação com as demais áreas do conhecimento.

$\mathrm{Na}$ pesquisa de campo observou-se que a dinâmica estabelecida nas escolas em reuniões pedagógicas e no planejamento é por disciplina, como diz Roseli (Egressa da LEdoC, 2015) "até os pais cobram as disciplinas, o caderno é por disciplinas". Existe uma cultura disciplinar nas escolas visitadas, principalmente no que se refere à sala de aula, às avaliações, ao plano de aula. Um dos momentos em que se consegue estabelecer uma relação para além das disciplinas seria nas atividades extra-sala-de-aula, como nas feiras da cultura e ou de ciências.

Destaca-se que dos oito (8) entrevistados, duas (2) conseguem incluir no planejamento atividades a partir de palavras geradoras, pois, já possuem experiência através da militância no MST e fazem parte do coletivo de educação daquele Movimento. Segundo Lima (2007), a educação para o MST deve considerar as raízes rurais vividas no campo, o que, para Caldart (2012), está relacionado a uma realidade específica, onde a educação se dá na coletividade e na luta pela sua humanidade, enquanto Sem Terra.

Apesar de muitas escolas não assumirem em seu Projeto Político Pedagógico (PPP) e nos planejamentos uma educação contextualizada e interdisciplinar, compreende-se que a construção desse processo é importante, pois a prática educativa está relacionada a uma dinâmica social, política e cultural. Sendo assim, por se tratar de uma escola conquistada em um território de assentamento, Roseli (Egressa da LEdoC, 2015) defende que "as lutas façam parte da dinâmica da escola, que precisa ir além dos conteúdos, se envolvendo, assim, com a história e memória do assentamento".

Nas escolas do campo na Amazônia Paraense, esse espaço, na maioria das vezes, é o único espaço público, com representação política estatal, e o professor torna-se o mediador da relação Estado e comunidade. Neste sentido, a formação de educadores do campo precisa ser um espaço de reflexão sobre a prática educativa, para que possa contribuir na transformação da realidade da educação inserida nos meios rurais. Por isso, "as necessidades presentes na escola do campo exigem um profissional com uma formação mais ampliada, mais totalizante, já que ele tem de dar conta de uma série de dimensões educativas presentes nessa realidade". (MARTINS \& ROCHA, 2009, p. 41). A ação do educador do campo está inserida no processo de formação de seus alunos, respeitando suas peculiaridades, ou seja, seus modos de vida, cultura e saberes. 


\section{Considerações finais}

A prática educativa produz uma práxis inventiva e criadora no conhecimento, na cultura e na ação política. Para Freire (2010), essa noção está na base do educar, ao relacionar o sentido de humanidade desses sujeitos que vivem, sentem, se envolvem, fazendo com que o educador traga tudo isso para si na sua compreensão do ser docente. Essa construção se desenvolve no curso de formação, na experiência cotidiana, nas relações teoria e prática que vão se estabelecendo nas trajetórias dos sujeitos da pesquisa, que, mesmo sendo desafiados pela falta de estrutura das escolas, por gestores e coordenação pedagógica que não envolvem o coletivo, ainda assim, tem nítida esperança, nítida crença de que a educação transforma e cria novas possibilidades para educandos e educadores.

Nessa perspectiva, a prática educativa precisa possuir uma dimensão que fortaleça o diálogo e o respeito às diferenças. Nessa direção, o papel do educador é de fundamental importância. Principalmente em avançar na formação integral do ser humano, trazendo à tona as dimensões socioambientais e o compromisso sócio-político, contribuindo no processo da consciência coletiva, possibilitando, assim, minimizar as desigualdades e ampliar as possibilidades de melhoria de vida das populações do campo.

\section{Referências}

ARROYO, M. G. Pedagogias em movimento: o que temos a aprender dos movimentos sociais? Revista Currículo sem fronteiras, v. 3, n. 1, p. 28-49, jan./jul., 2003. Disponível em: http://www.curriculosemfronteiras.org. Acesso em: 31 mar. 2017.

ARROYO, M. G. A escola e o movimento social: relativizando a escola. ANDE, n. 12, p. 16$21,1989$.

BANDEIRA. H. M. M; IBIAPINA, I. M. L. Prática educativa: entre o essencialismo e a práxis. Revista da FAEEBA - Educação e Contemporaneidade, Salvador, v. 23, n. 42, p. 07-117, jul./dez. 2014.

BARRETO, V. Paulo Freire para educadores. São Paulo: Arte \& Ciência, 1998.

BARDIN, L. Análise de conteúdo. Lisboa: Edições 70, 2012.

BERNARDES, S. T. de A. Um gosto poético: interações teoria e prática na formação do professor. Revista profissão docente on-line, Uberaba, v. 9, n. 21, p. 19-40, jan./jul. 2009. Disponível em: http://www.revistas.uniube.br/index.php/rpd/article/viewFile/227/378. Acesso em: 07 abr. 2017.

BRASIL. Lei n. 9.394, de 20 de dezembro de 1996. Que estabelece as Diretrizes e Bases Educação Nacional. Diário Oficial da União, Brasília, DF, 20 dez. 1996. Disponível em: http://www.planalto.gov.br. Acesso em: 12 fev. 2017.

CALDART, R. S. Educação do Campo. São Paulo: Expressão Popular. p. 257-265. Verbete do Dicionário da Educação do Campo, 2012.

FREIRE, P. Pedagogia do Oprimido. Rio de Janeiro: Paz e Terra, 1987. 
FREIRE, P. Pedagogia da esperança. São Paulo: Paz e Terra, 1992.

FREIRE, P. A importância do ato de ler em três artigos que se completam. São Paulo: Cortez, 2001.

FREIRE, P. Pedagogia da autonomia. São Paulo: Editora Paz e Terra, 2014

FREIRE, P. S. Pedagogia da práxis: o conceito do humano e da educação no pensamento de Paulo Freire. 2010. 147 f. Dissertação (Mestrado em Educação) - Programa de Pós-Graduação em Educação, Universidade Federal de Pernambuco, Recife, 2010.

KRAMER, S. Por entre as pedras: arma e sonho na escola. 3. ed. São Paulo: Ática, 2003.

LIMA, A. R. S. de. Cartografia de saberes nas práticas Educativas Cotidianas do Movimento dos Trabalhadores Rurais Sem Terra - MST na Amazônia Paraense. 2007. 266 f. Dissertação (Mestrado em Educação) - Programa de Pós-Graduação em Educação, Universidade do Estado do Pará, Belém-PA, 2007.

MARTINS, A. A. ROCHA, M. I. A. (Org.). Licenciatura em Educação do Campo: Histórico e projeto político-pedagógico. Educação do Campo, desafios para a formação de professores. Belo Horizonte/ MG: Autêntica Editora, 2009.

MACÊDO, M. M. O desenvolvimento de uma educação contextualizada como liberdade. Disponível em: http://www.coloquiointernacional.unimontes.br/2008/arquivos/90magdamartinsmacedo.pdf. Acesso em: 05 jun. 2017.

RODRIGUES, C. L.; AMARAL, M. B. Problematizando o óbvio: ensinar a partir da realidade do aluno. In: CONGRESSO DA ASSOCIAÇÃO NACIONAL DE PÓSGRADUAÇÃO E PESQUISA EM EDUCAÇÃO, 19., Caxambu, 1996. Anais... Caxambu: ANPED, 1996. p. 197.

SCHMITT, M. A. Ação-Reflexão-Ação: a prática reflexiva como elemento transformador no cotidiano educativo. Protestantes em Revista, São Leopoldo, RS, v. 25, maio-ago. 2011.

SILVA J.; RAMOS M. M. S. Prática pedagógica numa perspectiva interdisciplinar. http://leg.ufpi.br/subsiteFiles/ppged/arquivos/files/eventos/200.gt3/GT3_2006_08.PDF. 2006. Acessado em: 18/04/2016.

VÁZQUEZ, A. S. Filosofia da práxis. Tradução Luiz Fernando Cardoso. 2. ed. Rio de Janeiro: Paz e Terra, 1977.

VEIGA, I. P. A. A prática pedagógica do professor de Didática. 2. ed. Campinas: Papirus, 1992.

\section{Sobre a autora}

Márcia Cristina Lopes e Silva: Pedagoga, com Mestrado em Agricultura Familiar (UFPA) e Doutorado em Educação (UFC). Professora do IFPA, Campus Belém, nas licenciaturas e na pós-graduação. Lidera o grupo de pesquisa em Formação de professores Saberes e práticas educativas na Amazônia paraense (GPFOP).

E-mail: lilith.marcia@hotmail.com. 